\title{
Diatom frustule-filled epoxy: Experimental and numerical study of the quasi-static and high strain rate compression behavior
}

\author{
A. Taşdemirci ${ }^{\text {a }}$, S. Yüksel ${ }^{\text {a }}$, D. Karsu ${ }^{\text {a }}$, E. Gültürk ${ }^{\text {a }}$, I.W. Hall ${ }^{\text {b }}$, M. Güden ${ }^{\text {a,c, }, *}$ \\ ${ }^{a}$ Department of Mechanical Engineering, Izmir Institute of Technology, Gülbahçe Köyü, Urla, Izmir, Turkey \\ ${ }^{\mathrm{b}}$ Department of Mechanical Engineering, University of Delaware, Newark, DE, USA \\ ${ }^{\mathrm{c}}$ Center for Materials Research, Izmir Institute of Technology, Gülbahçe Köyü, Urla, Izmir, Turkey
}

Received 10 March 2007; received in revised form 5 July 2007; accepted 6 July 2007

\begin{abstract}
In this study, centric type diatom frustules obtained from a diatomaceous earth filter material were used as filler in an epoxy resin with a weight percentage of $15 \%$ in order to assess the possible effects on the compressive behavior at quasi-static and high strain rates. The high strain rate testing of frustule-filled and neat epoxy samples was performed in a split-Hopkinson pressure bar (SHPB) set-up and modeled using the commercial explicit finite element code LS-DYNA 970. Result has shown that $15 \%$ frustule filling of epoxy increased both modulus and yield strength values at quasi-static and high strain rates without significantly reducing the failure strain. Microscopic observations revealed two main deformation modes: the debonding of the frustules from the epoxy and crushing/fracture of the frustules. The modeling results have further confirmed the attainment of stress equilibrium in the samples in SHPB testing following the initial elastic region and showed good agreement with the experimental stress-time response and deformation sequence of the samples in high strain rate testing.
\end{abstract}

(C) 2007 Elsevier B.V. All rights reserved.

Keywords: Diatom frustules; Frustule-filled epoxy; Compression; High strain rate

\section{Introduction}

Diatoms are single-celled algae, living in aquatic environments [1]. The shell of the diatoms, known as a frustule, is made of nano-sized silica particles with an intricate 3D structure. When these aquatic plants cells die, the silica shell/frustules form diatomaceous earth (diatomite) on the floor of the ocean. Diatomaceous earth is an abundant, extremely cheap material and extensively used in sound and heat insulation, abrasives, filters, absorbents, and explosives [2]. Recent studies have also shown that intricate microscale polymeric and ceramic structures including zirconia [3,4], gold nanostructures [5] and $\mathrm{MgO}$ and $\mathrm{TiO}_{2}$ structures [6] can be prepared with relatively simple processing steps using the diatom frustules as transient scaffolds, templates and in solid-gas displacement reactions, respectively. The potential engineering and medical applications

\footnotetext{
* Corresponding author at: Department of Mechanical Engineering, Izmir Institute of Technology, Gülbahçe Köyü, Urla, Izmir, Turkey. Tel.: +90 232750 7816; fax: +90 2327507890 .

E-mail address: mustafaguden@iyte.edu.tr (M. Güden).
}

of diatom frustules have also recently been proposed, including metal film membranes, pinpoint drug delivery and processing of nanopowder silica [7]. The surface area of diatomaceous earth was reported to be relatively high, $22 \mathrm{~m}^{2} / \mathrm{g}[8]$ and it was shown to decrease slightly as a result of heat-treatment [9].

Owing to the high surface area/volume ratio, diatom frustules may have potential for use as the reinforcing phase and/or filler in polymeric composites: this provided the motivation for the present study. Thermoset resins have also been shown to penetrate through the micropores of diatom frustule, showing the capability of forming mechanical interlocking between frustule and polymer matrix [3]. The mechanical properties of individual diatom frustules have also been measured recently using atomic force microscopy (AFM). The elastic modulus of the diatom frustule of T. punctigera was reported as $22.4 \mathrm{GPa}$ [10]. The modulus and hardness of diatom Navicula pelliclosa varied between 7 and $100 \mathrm{GPa}$ and 1 and $12 \mathrm{GPa}$, respectively, depending on the location of the measurements taken [11]. The variation in the mechanical properties of the diatom frustule is closely related to the different stages of the biomineralization process. Despite the absence of plastic deformation and the smooth fracture surfaces of 
the broken frustule, it was microscopically shown in a pennate diatom that the cracks traveled around the nano-silica spheres, $\sim 40 \mathrm{~nm}$, of the diatom frustule [12], increasing the area of the fracture and, hence, the energy needed to break the frustule.

The properties of polymers are known to be improved by the addition of various types of micron and nano-sized fillers. Fillers having high surface area/volume ratio are generally expected to result in better mechanical properties. High surface area is usually associated with small filler size and with very rough surfaces. In this study, centric type diatom frustules obtained from a diatomaceous earth filtering materials are used as filler in an epoxy resin in order to assess the possible effects of the frustule on the mechanical properties under compressive loads at both quasi-static and high strain rates. Such filled polymer can potentially be used as the matrix for the fiber reinforced composite backing plate of modern composite armor in which the energy absorption capabilities of the composite at quasi-static and high strain rates play a critical role in absorbing the kinetic energy of the projectiles [13]. The development of multi-layer material systems, consisting of hard and soft layers, also requires detailed experimental and numerical wave-propagation analysis of the individual layer materials [14]. Therefore, the deformation behavior of the filled composite and its neat matrix was modeled for possible future applications involving high strain rate deformation.

\section{Materials and testing methods}

\subsection{Diatom frustules}

The diatom frustules, obtained as diatomaceous earth filter material from a local vendor (Celatoms FW-60 grade from EaglePicher Filtration \& Mineral Inc.), were mostly cylindrical in shape, and appeared as short tubes with diameters of 8-15 $\mu \mathrm{m}$ and lengths of 3-20 $\mu \mathrm{m}$ (Fig. 1). These frustules contained rows of fine pores, $300-500 \mathrm{~nm}$ in diameter, aligned parallel to the tube-axis (Fig. 1). One of the ends of the frustules possessed a circular hole with a protruding outer rim as shown in Fig. 2(a), while the other end was closed with either a dense or porous layer and possessed finger-like protuberances as shown by arrows in Fig. 2(b). The finger-like protuberances were observed to inter-

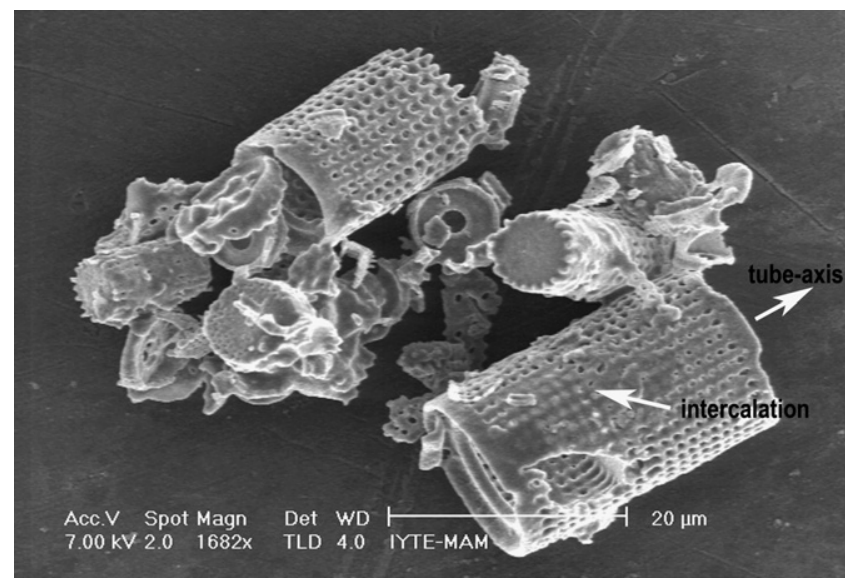

Fig. 1. SEM micrograph showing diatom frustules in varying sizes.

calate with other frustules forming paired chains of frustules (Fig. 1). XRD spectrum of the as-received diatom frustules had further shown crystalline cristobalite silica peaks (Fig. 3) in accordance with the supplier's specification of the presence of crystalline silica (ranging in weight concentration between 40 and $70 \%$ ). The as-received diatomaceous earth filter material contained relatively large pieces of various types of minerals and salts and relatively small broken frustule pieces, probably resulting from the flux-calcination process applied by the supplier. The large pieces of salts were removed by washing the powder with ethanol and then with dionized water several times. The powder was then wet-sieved below 325 mesh in order to remove the insoluble large particles. The small, broken frustule pieces were partly removed by sedimentation in dionized water. A suspension of the frustules was prepared and allowed to settle out for $1 \mathrm{~h}$ and then the decantate containing small or broken frustules pieces was poured out. This procedure was repeated three times and the remnant was dried at $120^{\circ} \mathrm{C}$ for $2 \mathrm{~h}$ in an oven before mixing with epoxy resin to prepare the filled epoxy matrices.

\subsection{Diatom frustule-filled epoxy}

A commercial epoxy resin Grandmer ${ }^{\circledR}$ VN-111 with a hardener was used as the epoxy matrix. The epoxy resin was mixed with $15 \mathrm{wt} \%$ diatom frustules under mechanical stirring for
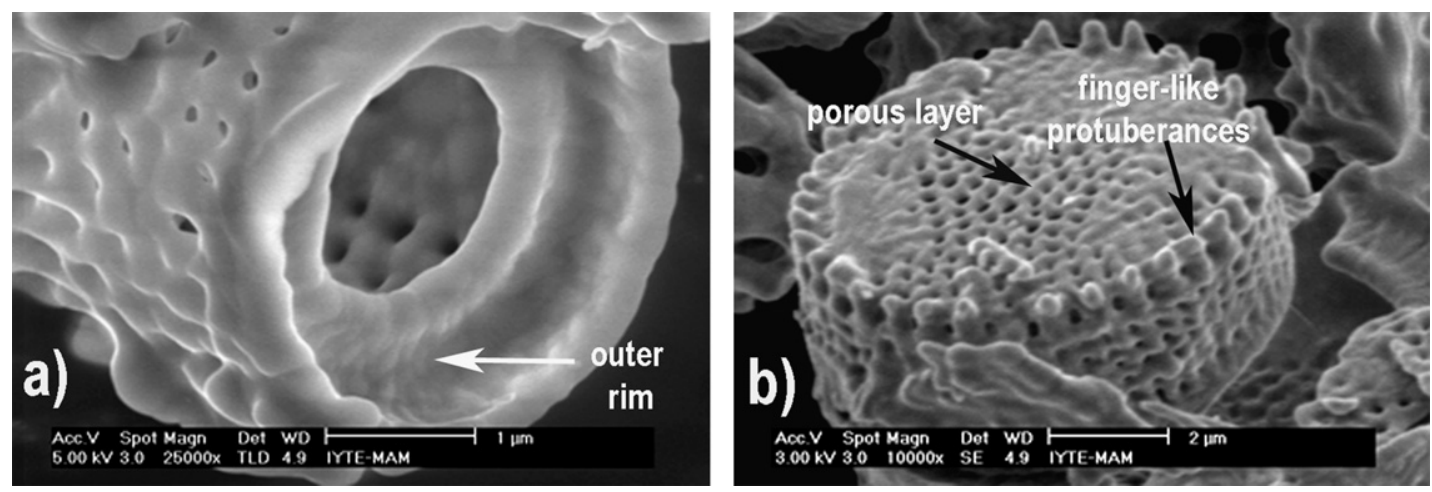

Fig. 2. SEM micrographs showing (a) the outer rim and (b) microporous closed end of the frustule. 


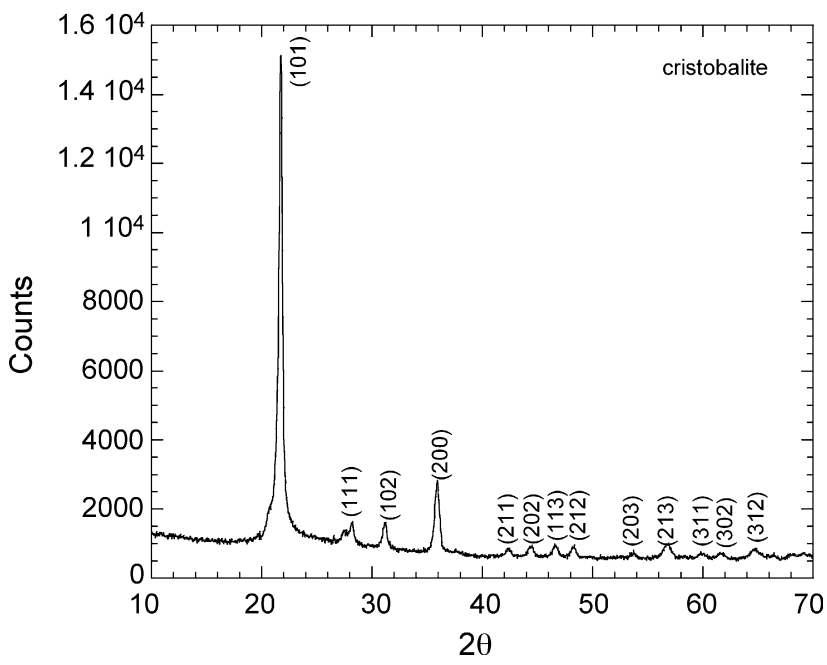

Fig. 3. XRD spectrum of the diatom frustule used in epoxy matrix showing cristobalite diffraction peaks.

$30 \mathrm{~min}$ at $100 \mathrm{rpm}$. After degassing under vacuum, the hardener was added, and the solution was gently mixed in order to avoid gas bubble formation. The polymer/frustule mixture was then cast into an $8 \mathrm{~cm} \times 8 \mathrm{~cm} \times 1.5 \mathrm{~cm}$ steel mold. The mixture was then cured at room temperature under vacuum inside the steel mold for $24 \mathrm{~h}$ followed by a post-curing treatment at $110^{\circ} \mathrm{C}$ for $2 \mathrm{~h}$. Using the above procedure, $8 \mathrm{~cm} \times 8 \mathrm{~cm} \times 1.5 \mathrm{~cm}$ plates of neat epoxy and diatom frustule-filled epoxy were prepared. The densities of epoxy and diatom frustule-filled epoxy were measured to be 1.123 and $1.21 \mathrm{~g} \mathrm{~cm}^{-3}$, respectively, by simply dividing the weight of the small cylindrical compression test specimens by their volume. The volume percentage of the filler was calculated to be $\sim 8 \%$ using the producer specified filler density $\left(2.33 \mathrm{~g} \mathrm{~cm}^{-3}\right)$. Applying the rule of mixtures gives a filled epoxy density of $1.3 \mathrm{~g} \mathrm{~cm}^{-3}$, which is $8 \%$ higher than the measured density. Cylindrical samples $9.78 \mathrm{~mm}$ in diameter and $14 \mathrm{~mm}$ in length were core-drilled perpendicular to the thickness direction for compression testing and compression tested at quasi-static strain rate of $0.0011 \mathrm{~s}^{-1}$ and high strain rates of $950-1000 \mathrm{~s}^{-1}$ and $1450-1550 \mathrm{~s}^{-1}$ in the split-Hopkinson pressure bar (SHPB) apparatus.

\subsection{Quasi-static and high strain rate testing}

Quasi-static compression tests were performed in a Shimadzu AG-I testing machine, while the high strain rate tests were conducted using a compression SHPB apparatus. The SHPB apparatus used consists of $19.05 \mathrm{~mm}$ diameter Inconel 718 bar, a $3450 \mathrm{~mm}$ long incident bar and $1850 \mathrm{~mm}$ long transmitter bar, and either a 356 or $712 \mathrm{~mm}$ long striker bar. The smaller striker bar was used to attain higher strain rates in the sample with lower final strains. Detailed information about the SHPB used is given in Ref. [14]. The strain rate $(\dot{\varepsilon})$, the strain $(\varepsilon)$ and the stress $(\sigma)$ of the tested sample were calculated using the following equations:

$\dot{\varepsilon}(t)=-\frac{2 C_{\mathrm{b}}}{L_{\mathrm{s}}} \varepsilon_{\mathrm{r}}(t)$ $\varepsilon(t)=-\frac{2 C_{\mathrm{b}}}{L_{\mathrm{s}}} \int_{0}^{t} \varepsilon_{\mathrm{r}}(t)$

$\sigma(t)=\frac{E_{\mathrm{b}} A_{\mathrm{b}}}{A_{\mathrm{s}}} \varepsilon_{t}(t)$

where $C_{\mathrm{b}}$ is the elastic wave velocity in the bar, $L_{\mathrm{S}}$ the sample length, $A_{\mathrm{s}}$ and $A_{\mathrm{b}}$ are the sample and bar cross-sectional areas and $t$ is the time, respectively. $\varepsilon_{\mathrm{r}}$ and $\varepsilon_{t}$ are reflected and transmitted strains measured from strain gages on the bar, respectively. The above equations are based on the assumption that the forces at sample-bar interfaces are equal. The experimental force equilibrium for the same incident and transmitter bars diameter is expressed as

$\sigma_{\mathrm{t}}(t)=\sigma_{\mathrm{i}}(t)+\sigma_{\mathrm{r}}(t)$

where $\sigma_{\mathrm{t}}, \sigma_{\mathrm{i}}$ and $\sigma_{\mathrm{r}}$ are the transmitted, incident and reflected stresses, respectively. The left and right sides of this equality are used in the so-called "one-wave" and "two-wave" analyses, respectively. Stress equilibrium within the sample is considered to be reached after three to five back and forth reflections of the wave in the sample and the time at which equilibrium is established depends on the wave transit time of the sample [15]. Since the transmitter bar of the used SHPB is shorter than the incident bar, the tensile wave reflected from the transmitter bar end separates the bars and, therefore, the sample deforms only once under compression.

Composite samples, compressed to various strains and up to failure at quasi-static and high strain rates, were metallographically prepared for microscopic analysis. Typical damage mechanisms operative prior to and during the failure were determined using microscopy techniques. The deformation process at high strain rates was observed by photographing the specimen sequentially in predetermined short time intervals (of the order of few microseconds) using a high-speed camera during SHPB testing. With the Ultra 8 high-speed camera used for the present study, a maximum of eight frames can be photographed at speeds up to 100 million frames/s. In the time domain, the interframe time can be varied between $10 \mathrm{~ns}$ and $1 \mathrm{~ms}$. The camera can be synchronized with the incident bar strain-gage or can be delayed to photograph the events of interest only.

\subsection{Modeling high strain rate deformation}

A three-dimensional SHPB finite element model was used to study the dynamic deformation behavior and stress-state of the diatom frustule-filled and neat epoxy specimens. The analyses were performed using the commercial explicit finite element code LS-DYNA 970. For each test modeled, the force and, hence, the stress values were calculated at several locations within the sample, including the sample front and back surfaces, as well as at the location of the strain gages on the incident and transmitter bars of the SHPB apparatus. The results calculated from the model were compared with the output from the strain gages on the incident and transmitter bars. The model has three components in contact: the incident and transmitter bars (the lengths of which are 3450 and $1850 \mathrm{~mm}$, respectively), and the specimen. 


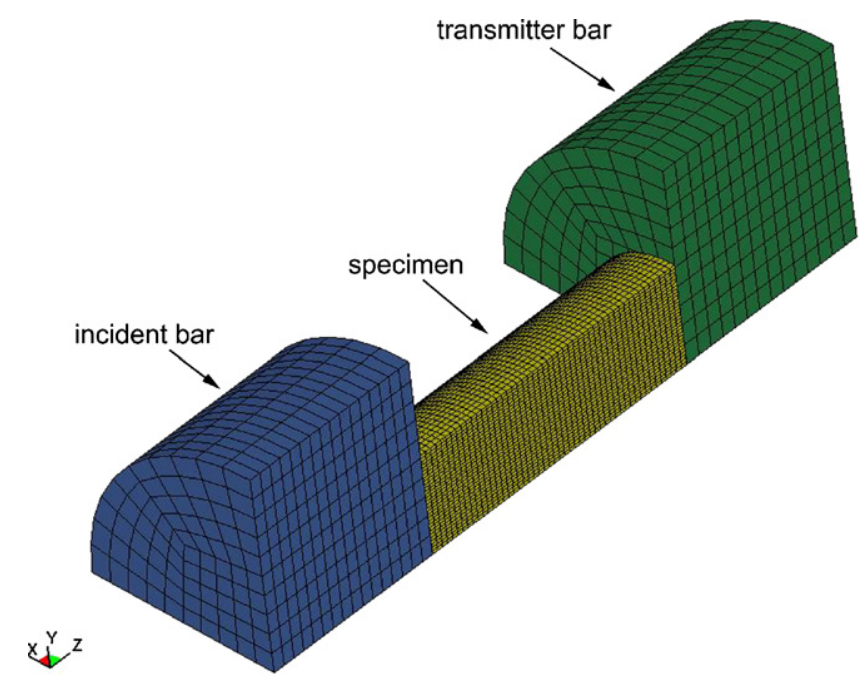

Fig. 4. The SHPB testing model of the incident and transmitter bars and the specimen (only specimen-bar interfaces section are shown).

The bar diameter is $19.05 \mathrm{~mm}$ and the diameter of the specimen is $9.78 \mathrm{~mm}$. Two axes of symmetry were assumed therefore only one quarter of the bar was modeled as shown in Fig. 4. The component materials were modeled with eight nodes solid elements and the bar-specimen interfaces were modeled with the automatic contact sliding interfaces without friction. A total of
Table 1

Material properties used in Finite Element Models

\begin{tabular}{lcclc}
\hline Material & $\begin{array}{l}\text { Modulus of } \\
\text { elasticity (GPa) }\end{array}$ & $\begin{array}{l}\text { Poisson } \\
\text { ratio }\end{array}$ & $\begin{array}{l}\text { Density } \\
\left(\mathrm{kg} \mathrm{m}^{-3}\right)\end{array}$ & $\begin{array}{l}\text { Proportional } \\
\text { limit (MPa) }\end{array}$ \\
\hline Epoxy & 3.46 & 0.35 & 1133.0 & 113.0 \\
Diatom-filled epoxy & 3.94 & 0.35 & 1206.0 & 128.4 \\
Inconel & 207.0 & 0.30 & 7850.0 & - \\
\hline
\end{tabular}

75 elements were used in the model for the cross-section, which provided 10 elements across the radius of the bars and a total of 400 elements were used along the length of the bar. Mesh biasing along the bar axis was utilized to refine the meshes at the contact interfaces. Further details of the modeling procedure may be found elsewhere [14].

The material properties used in the finite element code are tabulated in Table 1. The neat and frustule-filled epoxy were modeled with a piecewise linear plasticity material model which is an elasto-plastic material model with an arbitrary stress-strain curve and in which an arbitrary strain rate dependency can be defined. A fully viscoplastic formulation is optional for the material model and this option was used throughout the calculations [16]. Experimentally generated stress versus strain curves are used as input to LS-DYNA. The Inconel bars were modeled with an isotropic elastic material model. Force equilibrium in the specimen is further checked numerically using a dimensionless (a)

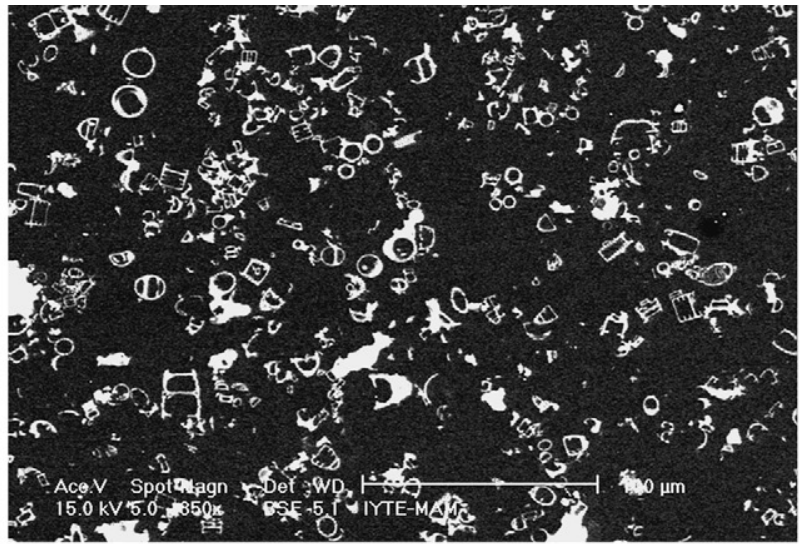

(b)

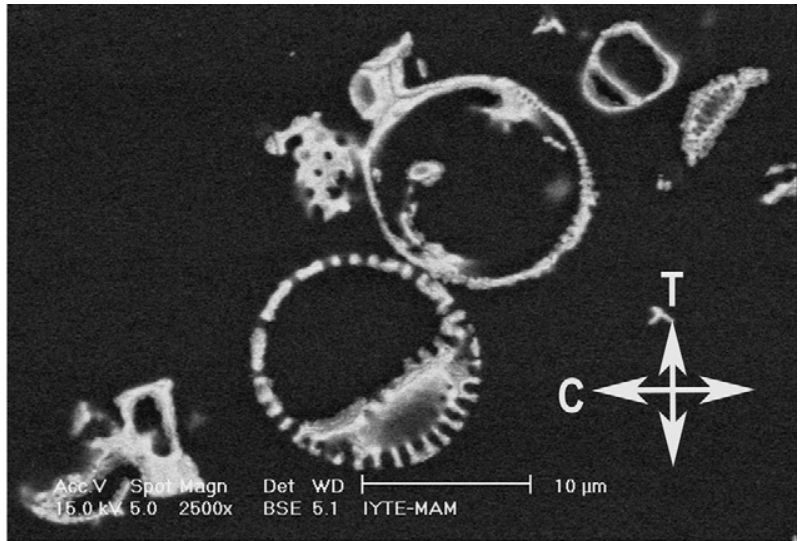

(c)

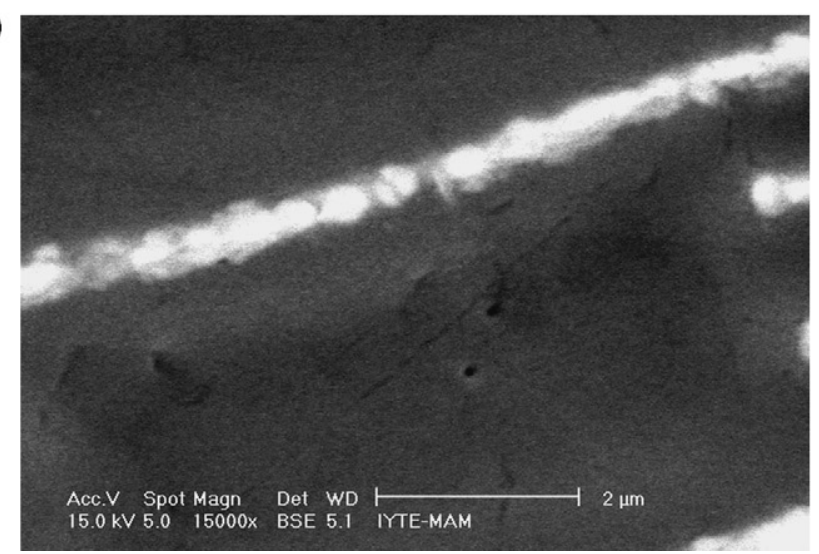

Fig. 5. SEM micrographs of the diatomaceous earth/epoxy matrix showing (a) distribution of the frustules in the matrix, (b) completely filled frustules (normal to the frustule tube axis) and (c) the wall of a frustule. $C$ denotes compression axis and $T$ thickness of the epoxy plate. 
number, $R[15]$ :

$R=-\frac{2\left(F_{1}-F_{2}\right)}{F_{1}+F_{2}}$

where $F_{1}$ and $F_{2}$ are the SHPB test sample front and back surface forces, respectively. This number is a measure of the extent of deviation from stress equilibrium in the specimen, which can further be compared with the experimental force equilibrium given in Eq. (4).

\section{Results and discussion}

\subsection{Microstructure and deformation behavior}

Fig. 5(a) shows diatom frustule distribution through the thickness of the prepared frustule-filled epoxy plate. In this (contrast inverted) scanning electron microscope (SEM) micrograph, $C$ and $T$ refer the compression axis and thickness directions, respectively. It is noted in Fig. 5(a) that the frustules' tube-axes are preferentially aligned in the plane normal to the thickness of the plate as relatively few are aligned through the thickness, showing a nearly planar random tube-axis distribution in the plane normal to the plate thickness. The compression tests were, therefore, conducted parallel to the planar random plane. Fig. 5(b) shows two diatom frustules whose tube axes were aligned normal to the thickness of the plate. It is also seen in the same figure that the interiors of the tubes are completely filled with epoxy resin. A $500 \mathrm{~nm}$ thick tube-wall cross-section of a diatom frustule is further shown in Fig. 5(c). The pores on the frustule wall are seen to be completely infiltrated with the epoxy resin.

Typical SHPB engineering stress/strain and strain rate/strain curves of the filled epoxy are shown in Fig. 6. The sample failed at a strain of 0.28 . For a specific test, the strain rate becomes almost constant following the yield stress as also shown in the same figure. It is also noted in Fig. 6 that the force or stress equilibrium is attained at strains about 0.05 (corresponding to yield stress) at which the one- and two-wave solutions become

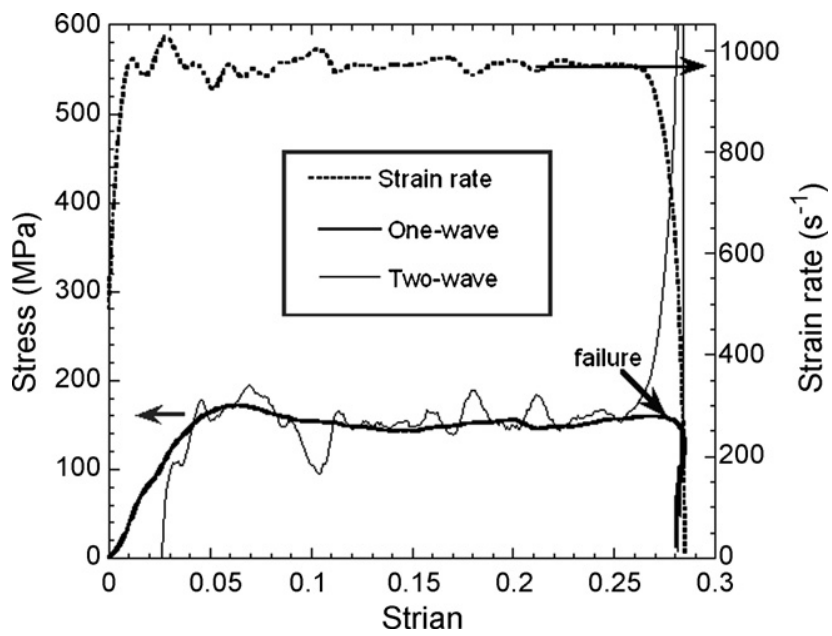

Fig. 6. Typical SHPB one- and two-wave stress-strain and strain rate-strain graphs of filled epoxy matrix tested at $950 \mathrm{~s}^{-1}$ until the failure strain of $\sim 0.28$.
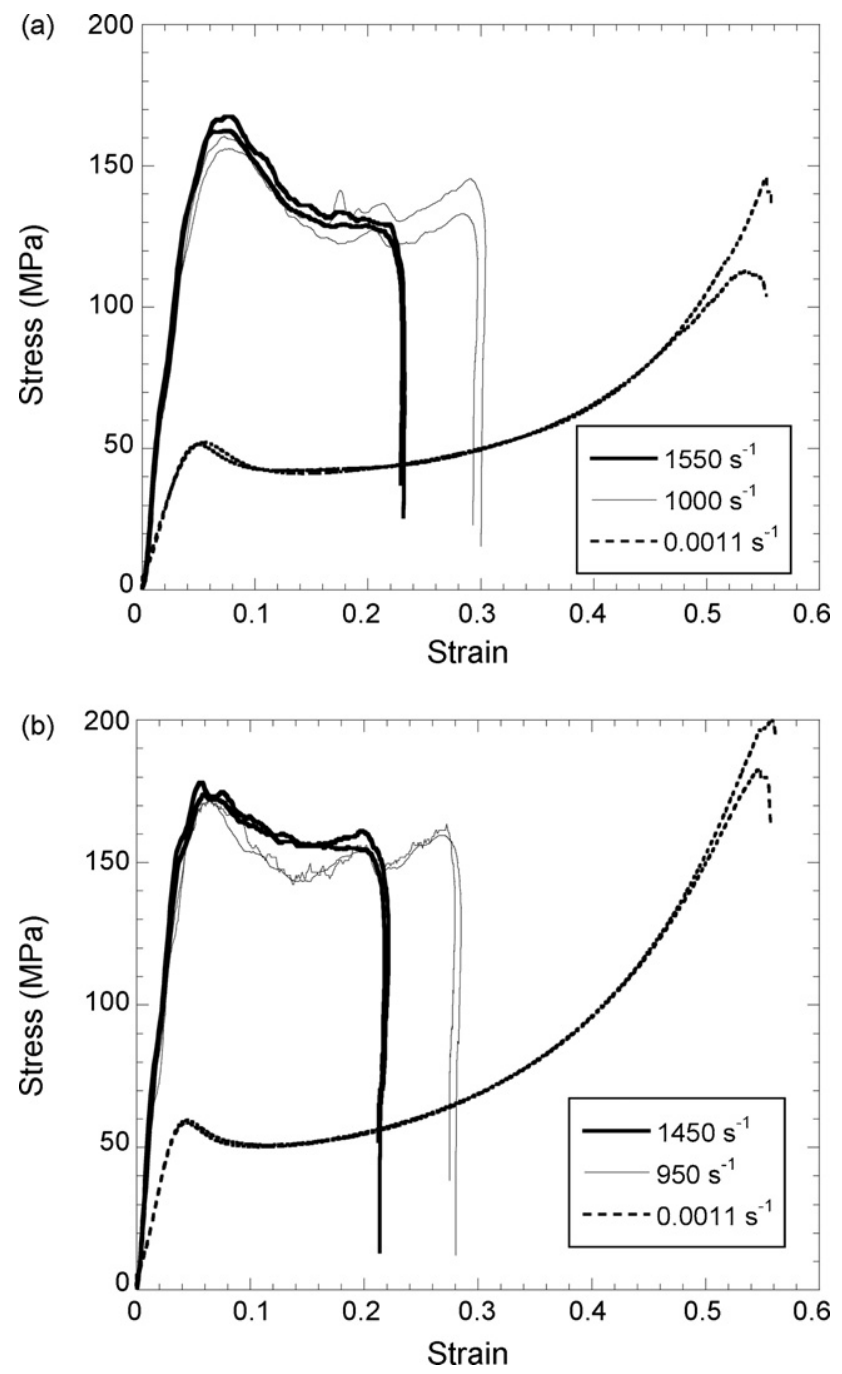

Fig. 7. Compression stress-strain graphs of (a) neat epoxy and (b) frustule-filled epoxy at quasi-static and dynamic strain rates.

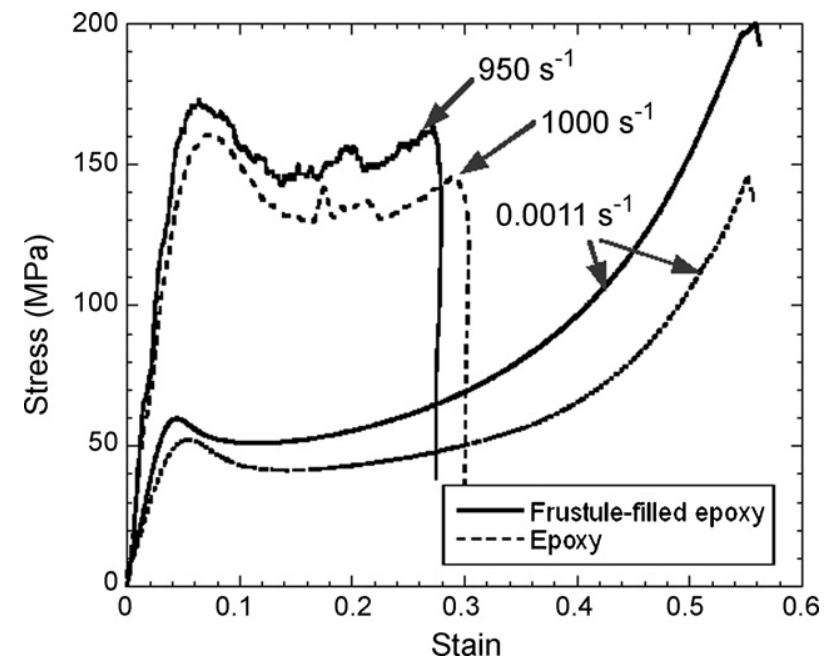

Fig. 8. Comparison of stress-strain curves of epoxy and frustule-filled epoxy and similar strain rates (samples tested until failure). 
(a)

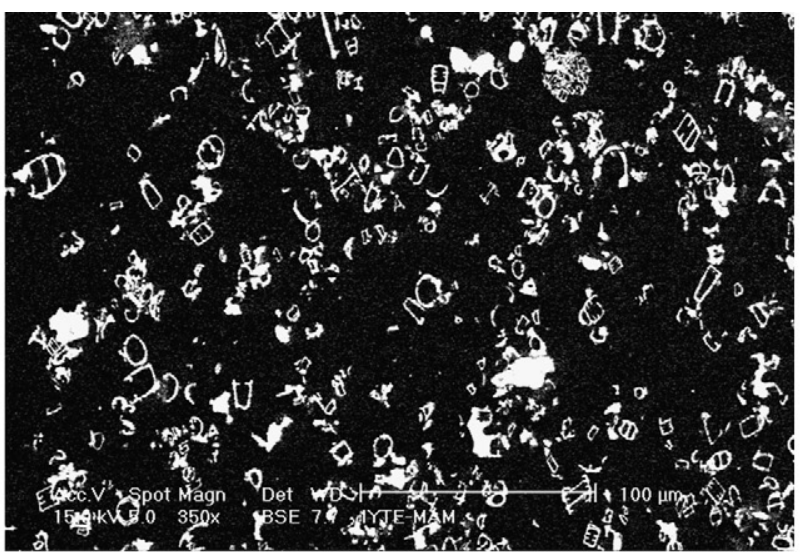

(c)

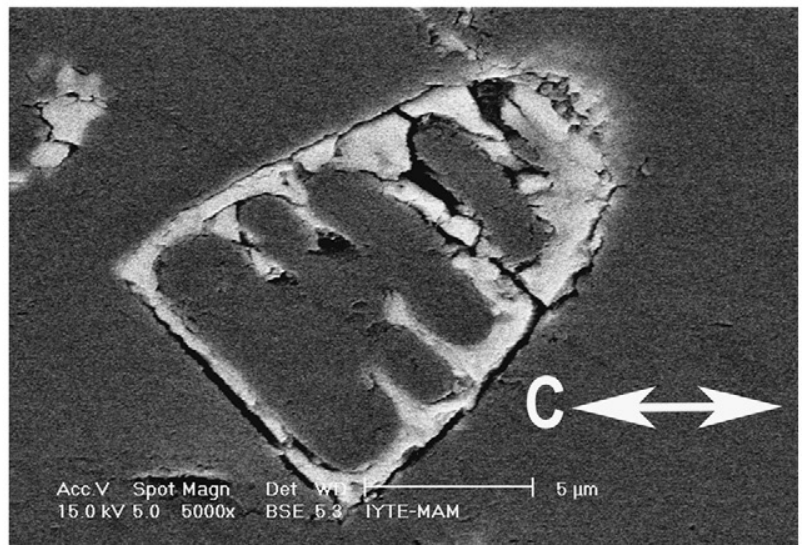

(b)

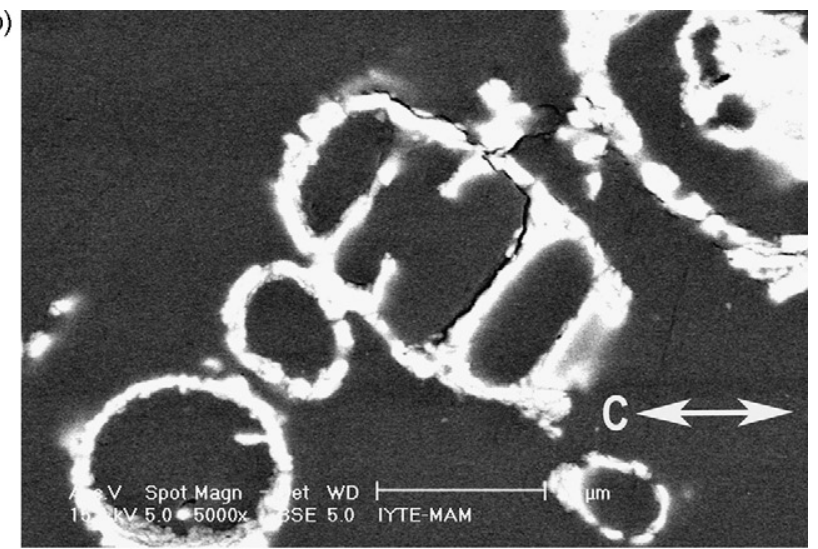

(d)

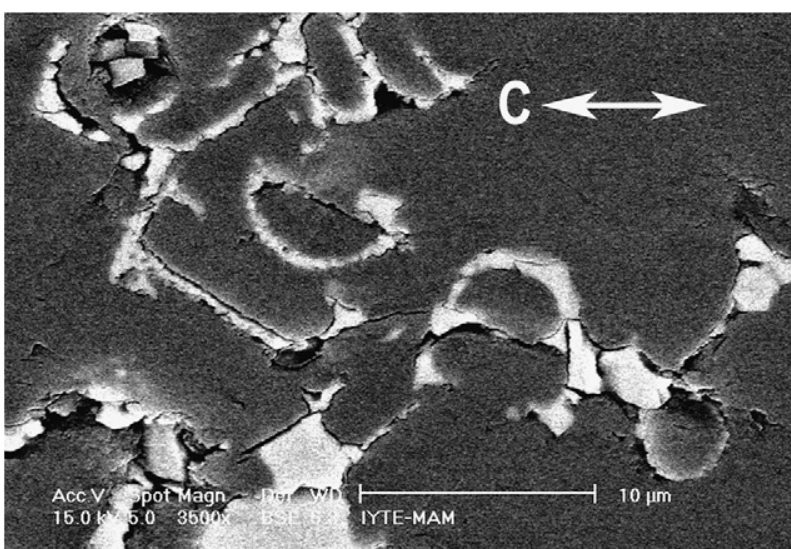

Fig. 9. SEM micrographs of the polished cross-sections of the quasi-statically tested and recovered frustule-filled epoxy samples: (a) and (b) Sample tested at $0.0011 \mathrm{~s}^{-1}$ until $48 \%$ strain and (c) and (d) sample tested at $950 \mathrm{~s}^{-1}$ until $27 \%$ strain.

almost equal. Fig. 7(a) and (b) shows the typical compressive stress/strain curves of the neat epoxy and filled epoxy samples tested at quasi-static $\left(0.0011 \mathrm{~s}^{-1}\right)$ and the high strain rates, respectively $\left(950-1550 \mathrm{~s}^{-1}\right)$. For both samples, the yield and flow stresses increased significantly at high strain rates, clearly proving the matrix dominated high strain rate behavior of the filled epoxy.

In Fig. 8, the stress-strain curves of epoxy and frustulefilled epoxy samples are shown for comparison at similar strain rates. At both strain rates, filled-composite samples show higher modulus, yield and flow stresses than those of neat epoxy. The measured average mechanical properties of the neat epoxy and frustule-filled epoxy, elastic modulus, yield and failure stresses and failure strain are tabulated in Table 2. As tabulated, the frustule addition increases elastic modulus and yield stress by $35 \%$ and $15 \%$ at $0.0011 \mathrm{~s}^{-1}$ and $14 \%$ and $8 \%$ at $950-1000 \mathrm{~s}^{-1}$, respectively. It is also noted in Table 2 that although the failure strains of the epoxy and frustule-filled epoxy decreased about $50 \%$ at high strain rate compared to the quasi-static strain rate, this was a strain rate effect and not linked to the frustule addition itself. In fact, frustule addition did not itself lead to any significant decrease in failure strain of the epoxy at the studied volume fractions.

Fig. 9(a) shows an SEM micrograph of a frustule-filled epoxy sample tested at $0.0011 \mathrm{~s}^{-1}$ to a strain of $48 \%$. As a result of the compressive loading, the frustules' tubes undergo severe fragmentation in the deformed sample as compared with undeformed sample shown in Fig. 5(a). This also partly proves the homogeneous loading of the frustules during compression until quite large strains. The failure mechanism of the filled epoxy is observed to be debonding of the frustule walls from the epoxy resin at both quasi-static and high strain rates as seen in Fig. 9(b) and (c). Fig. 9(d) shows crack progression in a sample tested at high strain rates through a shear band region at $\sim 45^{\circ}$ to the load-

Table 2

Mechanical properties of epoxy and diatom frustules filled epoxy at quasi-static and high strain rates

\begin{tabular}{lcccc}
\hline Property & $\begin{array}{l}\text { Epoxy quasi-static } \\
\left(0.0011 \mathrm{~s}^{-1}\right)\end{array}$ & $\begin{array}{l}\text { Epoxy high strain } \\
\text { rate }\left(1000 \mathrm{~s}^{-1}\right)\end{array}$ & $\begin{array}{l}\text { Diatom frustule/epoxy } \\
\text { quasi-static } \\
\left(0.0011 \mathrm{~s}^{-1}\right)\end{array}$ & $\begin{array}{l}\text { Diatom frustule/epoxy } \\
\text { high strain rate }\left(950 \mathrm{~s}^{-1}\right)\end{array}$ \\
\hline Elastic modulus (GPa) & $1.29(1.28-1.30)$ & $3.46(3.4-3.55)$ & $1.75(1.7-1.8)$ & $3.94(3.91-3.97)$ \\
Yield stress (MPa) & $51.8(51-53)$ & $158(155-160)$ & $59.6(58.6-60.7)$ & $171(170-173)$ \\
Failure stress (MPa) & $135(120-145)$ & $134125-145$ & $189(182-197)$ & $159(155-163)$ \\
Failure strain & $0.542(0.535-0.543)$ & $0.286(0.28-0.29)$ & $0.54(0.52-0.56)$ & $0.273(0.27-0.276)$ \\
\hline
\end{tabular}


ing axis. The cracks seen in this micrograph follow the sites of the debonded frustules.

The higher rate of frustule breakage at high strain rates is further confirmed by microscopic analysis of the fracture surfaces of the completely failed samples. Extensive microscopic observations have shown that the fracture surfaces of the samples tested at high strain rate generally contain a higher number of fragments of crushed frustules as compared with the those of the samples tested at quasi-static strain rates, see for example Fig. 10(a) and (b). Microscopic analysis of the fracture surfaces of samples tested at quasi-static strain rate also reveals the debonding and crushing of the frustules into several pieces, (Fig. 11(a)). The epoxy ligaments seen on the debonded and separated frustule in Fig. 11(b) again confirm complete epoxy infiltration into the pores of the frustules. Fig. 11(b) also shows that the cracks on the frustule follow the pores. At high strain rates, the frustules fractured into many small pieces as shown in Fig. 11(c), proving the larger degree of damage accumulation in samples tested at high strain rates. It is also quite possible that the debonded frustules crush more efficiently in high strain testing in between the two-fractured surfaces, while at quasi-static strain rates the test stops after the failure. Therefore, further investigations are required to clarify the effect of strain rate on the crushing behavior of the frustules.

The appearance of multiple-fractures of individual frustules shows a relatively strong frustule adhesion to the epoxy matrix as well as extensive mechanical interlocking. The interlocking is due to the epoxy infiltration partly into the pores parallel to the frustule tube axis and partly into the pores located at the back (a)

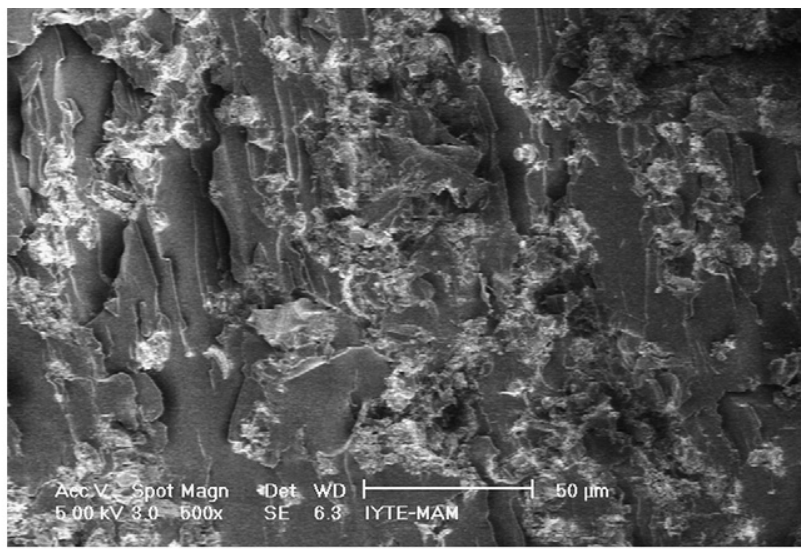

(b)

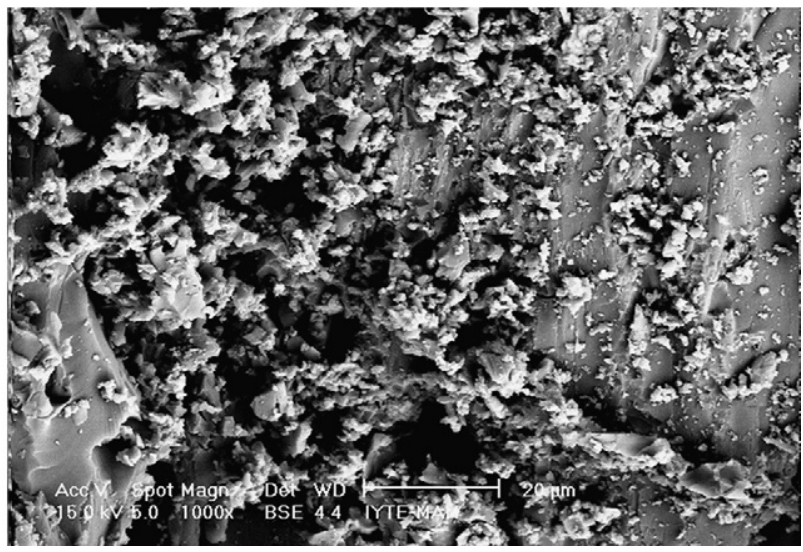

Fig. 10. SEM micrographs of the fracture surfaces of the frustule-filled samples tested at (a) $0.0011 \mathrm{~s}^{-1}$ and (b) $950 \mathrm{~s}^{-1}$.
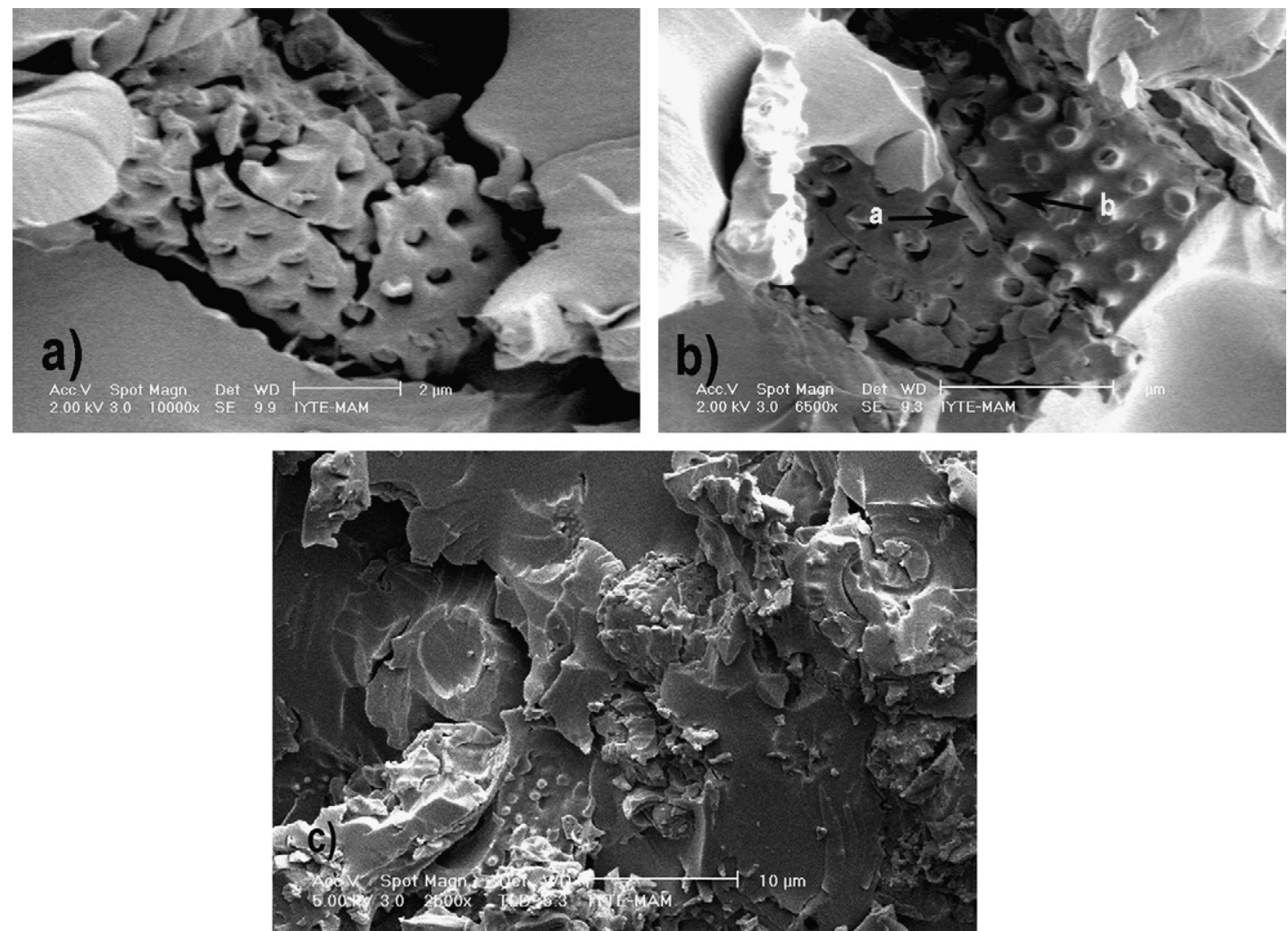

Fig. 11. SEM micrographs of the fracture surfaces of the filled samples showing fractured frustules in a sample tested at (a) and (b) $0.0011 \mathrm{~s}^{-1}$ and (c) $950 \mathrm{~s}^{-1}$. 
(a)

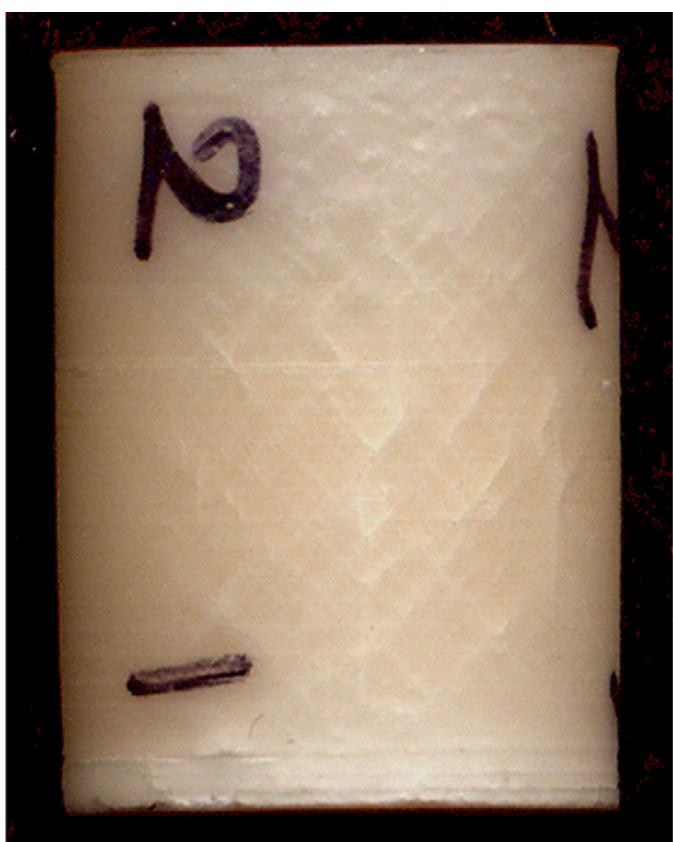

(b)

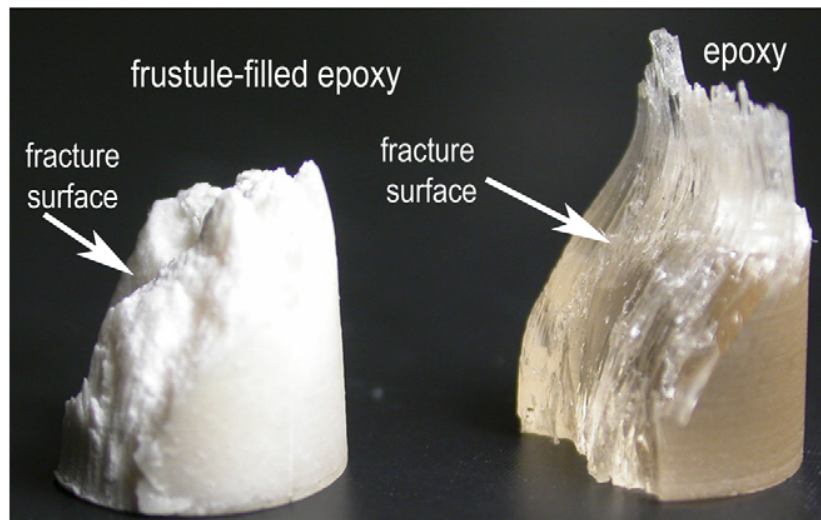

Fig. 12. (a) High strain rate deformed but not fractured frustule-filled epoxy sample tested at $1450 \mathrm{~s}^{-1}$ until a strain of $\sim 0.22$ and (b) fractured filled ( $950 \mathrm{~s}^{-1}, 0.28$ strain) and neat epoxy $\left(1000 \mathrm{~s}^{-1}, 0.30\right.$ strain) samples halves.
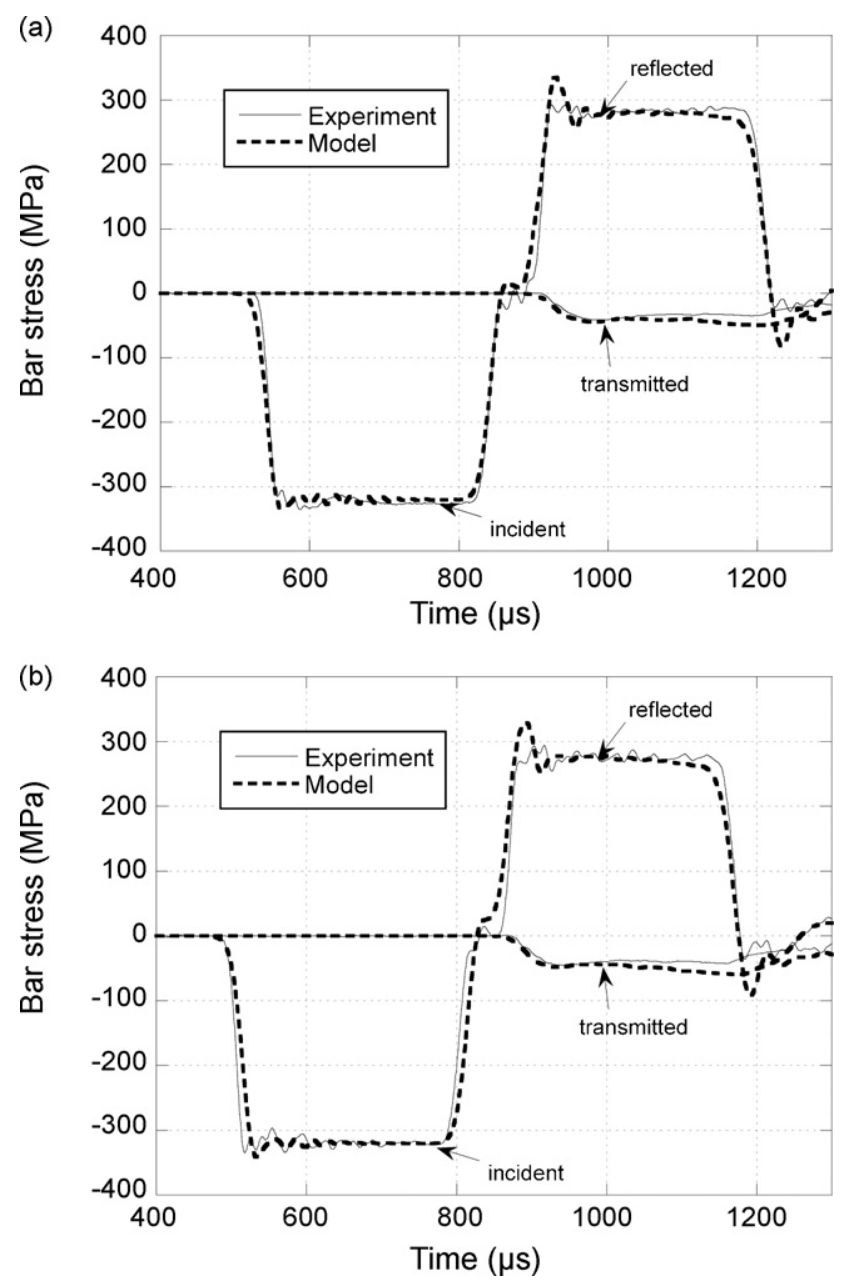

Fig. 13. Experimental and numerical bar stress vs. time: (a) epoxy and (b) frustule-filled epoxy sample deformed at 950 and $1000 \mathrm{~s}^{-1}$, respectively. surface of the frustule tube as well. This has also been proved with the micrographs of the fracture surfaces of the failed samples. The ligaments of epoxy in the crushed frustules' pores are clearly seen in Fig. 11(a)-(c). Due to mechanical interlocking, sections of the crushed frustule remain attached to the epoxy matrix as seen in these micrographs. The variation of the porosity size and content of the frustule along the tube axis may also result in local variations in the strength of the frustule bonding.

AFM studies on the inner and outer wall surfaces of a $C$. granii diatom frustule revealed $100-200 \mathrm{~nm}$ spherical $\mathrm{SiO}_{2}$ particles forming granular nanostructure with roughness depths of $70 \mathrm{~nm}$. [17]. The mechanical interlocking mentioned above between frustule and matrix should also be operative on the nanometer-scale, an effect similar to that in non-uniform carbon nano-tube reinforced polymers [18], which may result in extra

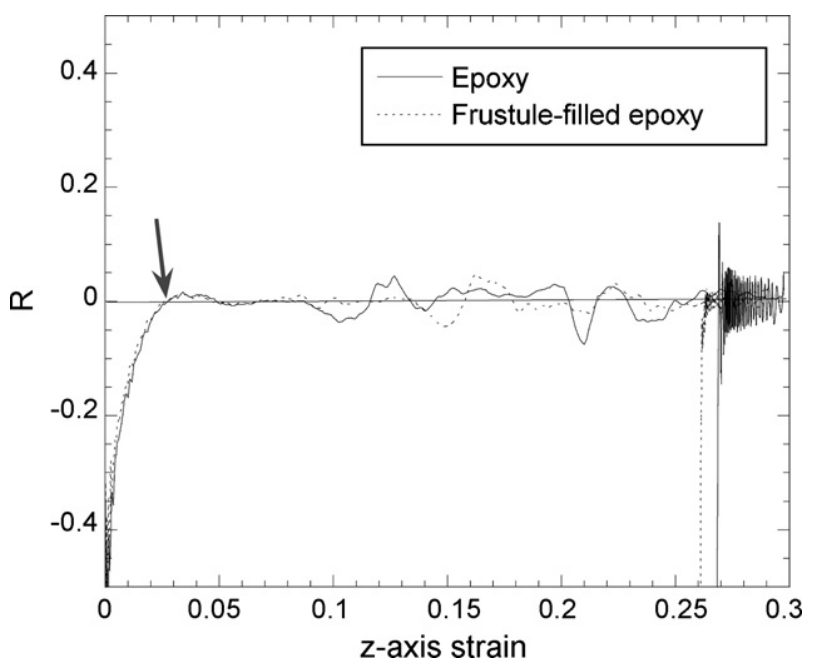

Fig. 14. Numerical $R$ vs. $z$-axis strain of epoxy and frustule-filled epoxy samples deformed at 950 and $1000 \mathrm{~s}^{-1}$, respectively. 
energy being expended to deform the matrix. The mechanical interlocking at the micro and/or nano-scale partly explains the relatively high fracture strains of the frustule-filled epoxy under compressive loading. The presumed mechanical interlocking is expected to become much more evident under tensile forces; therefore, tensile properties of the frustule-filled epoxy samples are being investigated in another parallel study.

Microscopic analysis on the deformed but not separated samples has shown evidence of shear band formation in filled and neat epoxy samples at both quasi-static and high strain rates (Fig. 12(a)). These bands eventually led to fracture in the sam- ple, at $\sim 45^{\circ}$ to the loading axis as shown in Fig. 12(b). The non-flat surfaces of the samples indicate that fracture has followed the small shear band regions, giving rise to a saw-tooth appearance particularly in the neat epoxy samples. The failure strains of the filled and neat epoxy samples are nearly the same at quasi-static and high strain rates, and this tends to confirm that the failure is matrix-dominated and not influenced by the presence of the frustules.

This study is an initial experimentation on the use of diatom frustules as filler in an epoxy matrix. The effects of filler volume content and the type, the use of surface active agents and the

(a)
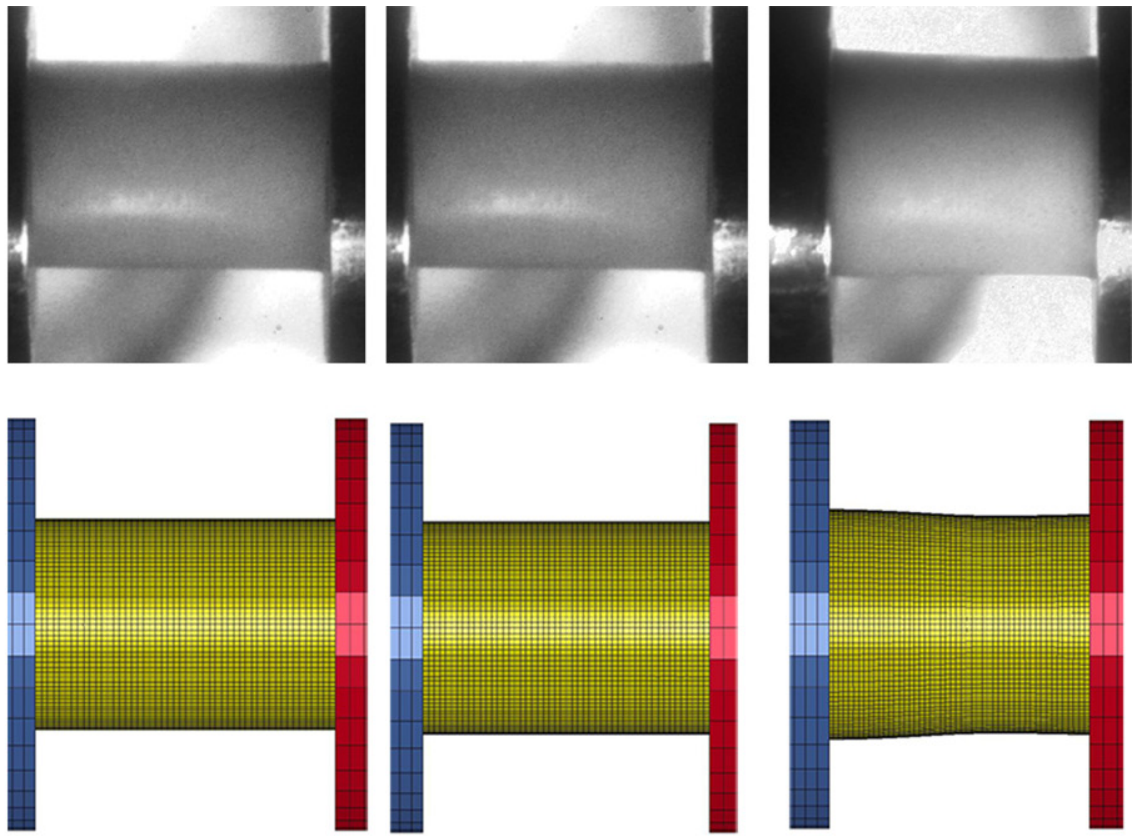

$0 \%$

$5 \%$

(b)
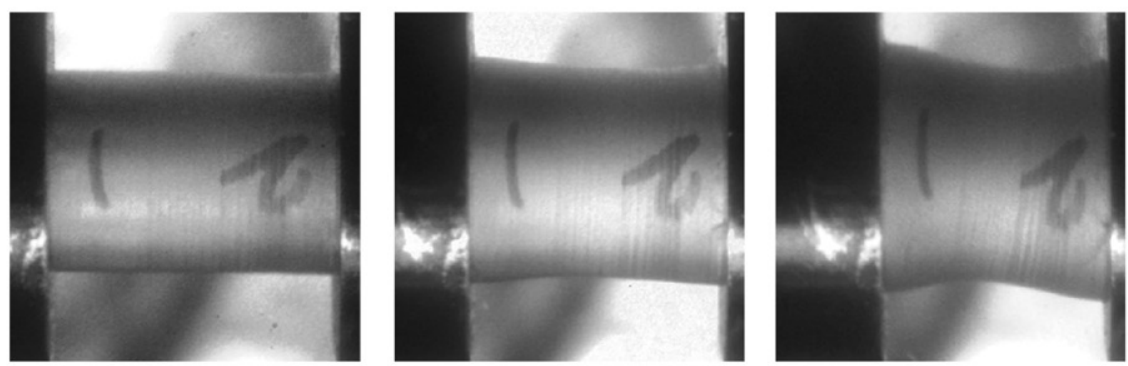

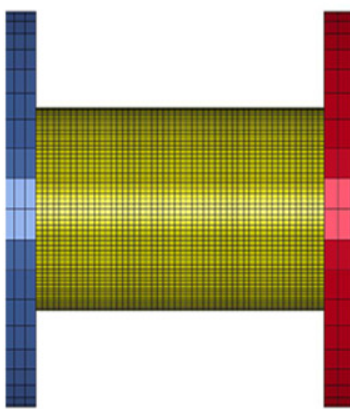

$0 \%$

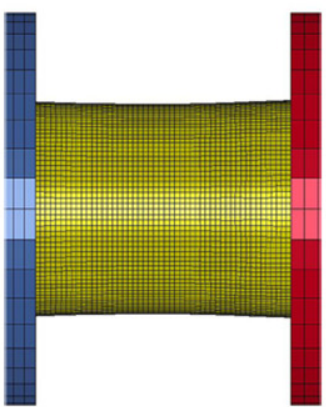

$10 \%$

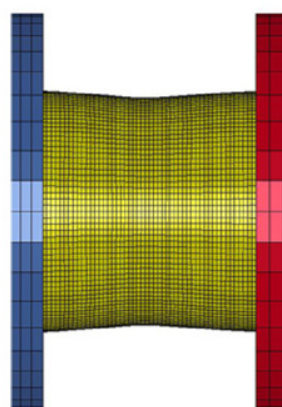

$24 \%$

Fig. 15. Experimental and numerical deformation history of (a) epoxy and (b) frustule-filled epoxy samples deformed at 950 and $1000 \mathrm{~s}^{-1}$, respectively. 
type of matrix resin should be further investigated in order to fully assess the potential use as filler in polymers. It is further noted that the use of diatom frustules as filler in polymers may give additional functionalities, which include improved wear resistance and fire retardant properties in addition to increased yield strength and modulus. The use of surface coupling agents may further increase the bonding between frustule and polymer. Further experiments are certainly needed to explore the mechanical and functional properties of these filled polymers. As stated previously the diatom frustule can easily be converted into $\mathrm{MgO}$ and $\mathrm{TiO}_{2}$ using solid-gas displacement reactions. Therefore, various types of filling materials with varying shapes and sizes can also be prepared using relatively cheap diatom frustules of various types.

\subsection{Modeling}

Fig. 13(a) and (b) compares experimental results from SHPB tests with the corresponding numerical calculations. These figures present the stresses in the bars resulting from the incident, reflected and transmitted waves as function of time for an epoxy sample tested at $1000 \mathrm{~s}^{-1}$ and for a frustule-filled epoxy sample tested at $950 \mathrm{~s}^{-1}$. Despite the small differences in stress values between experiment and model particularly at the beginning of the reflected wave and in the later part of the transmitted stresses, the shape of the model stress-time curve and the maximum stress values show excellent agreement with those of the experiments. This indicates that the model is indeed accurately capturing the mechanical property response of the samples to high strain rate deformation.

The numerical contact force history at the specimen-bar interfaces is used to calculate the dimensionless number, $R$, which indicates the deviation from homogeneous stress state within the sample and is shown in Fig. 14. The $R$-values are presented as a function of the longitudinal strain in the sample ( $z$-strain) and are an average strain calculated along the specimen length. The numerical prediction shows that during the SHPB testing of both materials, the value of $R$ is quite large during the initial phase of loading in the elastic portion; however, $R$ exponentially decreases to 0 and varies between \pm 0.05 for the rest of the loading period after about $3 \%$ strain. This numerical result corresponds closely with the experimentally found stress equilibrium based on the "one-wave" and "two-wave" equations mentioned above. Fig. 15(a) and (b) shows the experimental and numerical deformation sequences of the epoxy and frustule-filled epoxy sample at various strains. The similarities in the deformed shape of the samples between model and experiments shown in Fig. 15(a) and (b) further confirm the validity of the model and model parameters used.

\section{Conclusions}

In this study quasi-static $\left(0.0011 \mathrm{~s}^{-1}\right)$ and high strain rate (950-1550 s $\left.{ }^{-1}\right)$ compression behavior of a diatom frustule-filled (15wt\%) epoxy were investigated experimentally and numerically. For comparison, the compression behavior of the neat epoxy was also determined. The frustule tube axis distribution was found to be approximately planar random in a plane normal to the thickness of the epoxy plate molded in a rectangular steel die. The compression test was performed parallel to the planar random plane. Result has shown that $15 \%$ diatom frustule filling increases both modulus and yield strength of the epoxy matrix at quasi-static and high strain rates without significantly reducing the failure strain. Microscopic observations on the fracture surfaces and the mounted cross-sections of deformed samples have shown that the failure mechanisms were debonding of the frustule-epoxy interface and the fracture of the frustules. The model results have confirmed the stress equilibrium attainment in the sample following the elastic region and showed excellent agreement with the experimental stress-time response and deformation sequence of the samples during high strain rate testing in SHPB. These results confirm that significant benefits may be anticipated from the use of diatom frustules as reinforcements and fillers in polymeric materials.

\section{References}

[1] F.E. Round, R.M. Crawford, D.G. Mann, The Diatoms. Biology and Morphology of the Genera, Cambridge University Press, Cambridge, 1990.

[2] D. Werner, The Biology of Diatoms, University of California Press, Berkeley, CA, 1977.

[3] C.S. Gaddis, K.H. Sandhage, J. Mater. Res. 19 (2004) 2541-2545.

[4] J. Zhao, C.S. Gaddis, Y. Cai, K.H. Sandhage, J. Mater. Res. 20 (2005) 282-287.

[5] D. Losic, J.G. Mitchell, N.H. Voelcker, Chem. Commun. (2005) 4905-4907.

[6] K.H. Sandhage, R.L. Snyder, G. Ahmad, S.M. Allan, Y. Cai, M.B. Dickerson, C.S. Gaddis, M.S. Haluska, S. Shian, M.R. Weatherspoon, R.A. Rapp, R.R. Unocic, F.M. Zalar, Y. Zhang, M. Hildebrand, B.P. Palenik, Int. J. Appl. Ceram. Technol. 2 (2005) 317-326.

[7] K.M. Wee, T.N. Rogers, B.S. Altan, S.A. Hackney, C. Hamm, J. Nanosci. Nanotechnol. 5 (2005) 88-91.

[8] E.G. Vrieling, T.P.M. Beelen, R.A. van Santen, W.W.C. Gieskes, J. Biotechnol. 70 (1999) 39-51.

[9] R. Gören, T. Baykara, M. Marsoğlu, Br. Ceram. Trans. 101 (2002) $177-$ 181.

[10] C.E. Hamm, R. Merkel, O. Springer, P. Jurkojc, C. Maier, K. Prechtel, V. Smetacek, Nature 421 (2003) 841-843.

[11] N. Almqvist, Y. Delamo, B.L. Smith, N.H. Thomson, A. Bartholdson, R. Lal, M. Brezezinski, P.K. Hansma, J. Microscopy 202 (2001) 518-531.

[12] S.A. Crawford, M.J. Higgins, P. Mulvaney, R. Wetherbee, J. Phycol. 37 (2001) 543-554.

[13] Composite structure design guide, 1997-98, Composite armored vehicle program, United Defense L.P.

[14] A. Tasdemirci, I.W. Hall, B.A. Gama, M. Guden, J. Comp. Mater. 38 (2004) 995-1009.

[15] G. Ravichandran, G. Subhash, J. Am. Ceram. Soc. 77 (1994) 263-267.

[16] LSTC, LS-DYNA keyword user's manual. Livermore Software Technology Corporation. 2005.

[17] F. Noll, M. Sumper, N. Hampp, Nano Lett. 2 (2002) 91-95.

[18] L. Liao, Y. Ren, T. Xiao, in: Y.W. Mai, Z.Z. Yu (Eds.), Polymer Nanocomposites, Woodhead Publishing Limited, Cambridge, 2006, pp. 330-356. 